BMJ Paediatrics Open

\title{
Emergency department use and hospital admission in children following ambulatory surgery: a retrospective population-based cohort study
}

Monakshi Sawhney (D) ,' Elizabeth G VanDenKerkhof (D) , ${ }^{1}$ David H Goldstein (D) , 3 Xuejiao Wei, ${ }^{4}$ Genevieve Pare (D) , ${ }^{1}$ Ian Mayne (D) ${ }^{5}$ Joan Tranmer (iD ${ }^{1}$

\section{ABSTRACT}

Introduction Paediatric ambulatory surgery (same day surgery and planned same day discharge) is more frequently being performed more in Canada and around the world; however, after surgery children may return to hospital, either through the emergency department (ED) or through a hospital admission (HA). The aim of this study was to determine the patient characteristics associated with $E D$ visits and $H A$ in the 3 days following paediatric ambulatory surgery.

Methods This population-based retrospective cohort study used de-identified health administrative database housed at ICES and included residents of Ontario, younger than 18 years of age, who underwent ambulatory surgery between 2014 and 2018. Patients were not involved in the design of this study. The proportion of ED visit and HA were calculated for the total cohort, and the type of surgery. The ORs and 95\% Cls were calculated for each outcome using logistic regression.

Results 83468 children underwent select ambulatory surgeries. 2588 (3.1\%) had an ED visit and 608 (0.7\%) had a HA in the 3 days following surgery. The most common reasons for ED visits included pain (17.2\%) and haemorrhage (10.5\%). Reasons for HA included haemorrhage $(24.8 \%)$, dehydration $(21.9 \%)$, and pain (9.1\%).

Conclusions Our findings suggest that pain, bleeding and dehydration symptoms are associated with a return visit to the hospital. Implementing approaches to prevent, identify and manage these symptoms may be helpful in reducing ED visits or hospital admissions.

\section{Check for updates}

(c) Author(s) (or their employer(s)) 2021. Re-use permitted under CC BY-NC. No commercial re-use. See rights and permissions. Published by BMJ

For numbered affiliations see end of article.

Correspondence to Dr Monakshi Sawhney; mona. sawhney@queensu.ca
Paediatric ambulatory surgery (same day surgery and planned same day discharge) is being performed more frequently in Canada and around the world. When surgeries are performed on an ambulatory basis, it precludes the need for the patient to remain in hospital, the number of surgeries can be increased and costs are decreased. ${ }^{12}$ By minimising the time spent in the hospital, ambulatory surgery decreases the impact on families and risk of nosocomial infection.

\section{INTRODUCTION}

\section{What is known about the subject?}

$\Rightarrow$ Paediatric ambulatory surgery (same day surgery and same day discharge) is being performed more frequently.

$\Rightarrow$ After discharge to home, children and parents do return to the emergency department (ED) or are admitted to hospital (HA).

$\Rightarrow$ Children were more likely to have an ED visit or HA if they have comorbidities.

\section{What this study adds?}

$\Rightarrow$ Just under $4 \%$ of children had an ED visit or $\mathrm{HA}$ following elective ambulatory surgery in Ontario, Canada.

$\Rightarrow$ Findings suggest that pain, bleeding and dehydration symptoms are associated with a return visit to the hospital.

$\Rightarrow$ Providing parents and caregivers with strategies regarding managing pain and hydration at home may prevent ED or HA.

However, if children experience uncontrolled adverse effects following surgery, it can lead to an emergency department (ED) visit or hospital admission (HA). In Ontario, Canada, 1334972 people between the ages of 0 and 19 years had an ED visit in 2018-2019. ${ }^{3}$ It is unclear how many of these ED visits were related to ambulatory paediatric surgery.

Following tonsillectomy, cholecystectomy and orthopaedic surgery in children, the reported rates of return to hospital between 24 hours and 30 days after ambulatory surgery range from $1.1 \%$ to $14 \% .{ }^{4-10}$ Children were more likely to have an ED visit or HA if they had comorbidities including developmental delay, Down syndrome, attention deficit hyperactivity disorder, asthma, diabetes, obesity or cardiac disease..$^{24611}$ They were also more likely to return to hospital if they 
had surgery in the late afternoon or who have parents who did not speak the primary language of the country (eg, English). ${ }^{6} 11$ The most common reasons for ED visit or readmission include pain, dehydration, nausea, vomiting, haemorrhage and syncope. $.^{4-6} 8-1012$

These studies provide information regarding the unplanned healthcare use following ambulatory surgery. However, it is unclear how many and for which clinical problems paediatric patients have an ED visit or HA in the first 3 days following discharge after ambulatory surgery in Ontario. Services and systems could be put in place to prevent common adverse events to try to prevent return to hospital. The purpose of this study was to examine $\mathrm{ED}$ use and $\mathrm{HA}$ in the first 3 days after ambulatory surgery in children (17 years or younger) in Ontario. Three days following surgery was chosen to capture healthcare use most likely to be associated with surgery rather than other factors. The aims of this study were to determine the proportion of ED use and HA in children after common ambulatory surgery procedures, identify the surgical groups and patient characteristics associated with higher ED use or HA, and describe the top five reasons for ED use overall and top five reasons for ED use by surgical group in children. A similar study was conducted examining ED use and HA in the first 3 days after ambulatory surgery in adults. ${ }^{13}$

\section{METHODS}

\section{Study design and participants}

This population-based retrospective cohort study followed the STROBE reporting guidelines and conducted using de-identified administrative databases held by ICES (formerly the Institute of Clinical Evaluative Sciences). The Ontario-specific databases used included the Registered Persons Database (RPDB), Ontario Health Insurance Plan (OHIP), Ontario Marginalization Index (ONMARG), Client Agency Program Enrolment database (CAPE) and Corporate Provider Database (CPDB). The Canadian databases used included the Canadian Census, Canadian Institute for Health Information Same Day Surgery (CIHI-SDS), Discharge Abstract Database (CIHI-DAD) and National Ambulatory Care Reporting System (CIHI-NACRS) databases. These databases were linked using unique encoded identifiers and were analysed at ICES.

The cohort consisted of children between the age 0 and 17 years, residing in Ontario who underwent one of the commonly performed ambulatory surgical procedures as identified by CIHI between 1 January 2014 and 31 December 2018. The selection of surgical procedures was adapted from the CIHI's report of the most common ambulatory surgery procedures. ${ }^{14}$ Included surgical procedures were hernia-related muscle repair of the chest and abdomen, cholecystectomy, knee joint repair, release of nerves in the forearm, shoulder surgery, tonsillectomy and tympanic membrane procedures. Description of the specific diagnostic and surgical procedures that fall under these surgical categories is included in online supplemental appendix A. Children who did not have province of Ontario health insurance coverage 1 year before index date were excluded from this study. To ensure that only elective surgical procedures were included, patients were excluded if they had an ED visit immediately prior to their surgery. Patients who died on the day of surgery were also excluded. If the child underwent more than one ambulatory surgery between 2014 and 2018, only their first ambulatory surgery was included, as prior ambulatory surgery experience could influence the postoperative care that was provided at home and subsequently the healthcare utilisation.

The outcome of interest included any ED visit or HA within 3 days of the procedure. HA was exclusive of ED visit, and participants were not double counted. The main reason for an ED visit or a HA was captured from the CIHI-DAD or CIHI-NACRS. To ensure that HA following surgery was associated with a planned ambulatory surgery, the HA was cross-referenced between SDS database and the CIHI-DAD to confirm the surgery was booked as ambulatory, and the admission to hospital occurred after surgery was completed. The type of surgical procedure (main exposure variable) was captured from the CIHI-SDS Database. The Canadian Classification of Health Interventions (CCI) codes were used to classify surgical procedures. ${ }^{15}$ The CCI codes and companion surgical procedures are provided in online supplemental appendix A.

Demographic characteristics included age, sex and rurality of residence based on Rurality Index of Ontario 2008, and Local Health Integration Network (LHIN). ${ }^{16}$ Individual measures of socioeconomic status were not available in the databases; therefore, material deprivation was captured from the ON-MARG database. The ON-MARG database provides aggregate-level measures of socioeconomic status based on the neighbourhood, and considers variation in education, income and family composition. ${ }^{17}$ Primary care provider information, specifically the model of the usual provider of primary care, was obtained from CAPE and CPDB databases. ${ }^{18} 19$ The Johns Hopkins Aggregated Diagnostic Groups Version 10 (ADGs) was used to measure comorbidity, and ADGs were captured from CIHI-DAD, CIHI-NACRS and OHIP. ${ }^{20}$

\section{Data analysis}

Demographic data and clinical characteristics were summarised using measures of central tendency and spread or frequencies and percentages, as appropriate. Mean or proportion of patients were reported in the total cohort and those with at least one ED or HA, according to patient characterises and surgical category. Bivariate and multivariate logistic regression analyses were used to calculate the ORs and 95\% CIs for ED use and HA. In this study, ORs are used as a proxy of risk because incidence is rare $(<10 \%) .{ }^{21}$ Cholecystectomy was selected as the reference surgery for the purpose of interpreting the ORs. The rationale for selecting cholecystectomy was that 
Table 1 Demographic and clinical characteristics of children who underwent ambulatory surgery in Ontario between 2014 and 2018

\begin{tabular}{|c|c|c|c|}
\hline Characteristics & $\begin{array}{l}\text { Total } \\
\mathrm{N}=83468 \\
\mathrm{n}(\%) \\
\end{array}$ & $\begin{array}{l}\text { ED visits } \\
\mathrm{N}=2588 \\
\mathrm{n}(\%)\end{array}$ & $\begin{array}{l}\text { Hospital admission } \\
\mathrm{N}=608 \\
\mathrm{n}(\%)\end{array}$ \\
\hline Mean age in years $(\mathrm{SD})$ & 6.19 (SD 4.4) & 6.94 (SD 4.7) & 6.48 (SD 4.1) \\
\hline \multicolumn{4}{|l|}{ Sex } \\
\hline Female & $36744(44.0 \%)$ & $1274(49.2 \%)$ & $298(49.0 \%)$ \\
\hline Male & $46724(56.0 \%)$ & $1314(50.8 \%)$ & $310(51.0 \%)$ \\
\hline \multicolumn{4}{|l|}{ Material deprivation quintile } \\
\hline 1-Lowest & $19772(23.7 \%)$ & $513(19.8 \%)$ & $134(22.0 \%)$ \\
\hline 2 & $18280(21.9 \%)$ & $522(20.2 \%)$ & $133(21.9 \%)$ \\
\hline 3 & $15719(18.8 \%)$ & $478(18.5 \%)$ & $101(16.6 \%)$ \\
\hline 4 & $13822(16.6 \%)$ & $498(19.2 \%)$ & $95(15.6 \%)$ \\
\hline 5-Highest & $15347(18.4 \%)$ & $550(21.3 \%)$ & $129(21.2 \%)$ \\
\hline Missing & $528(0.6 \%)$ & $27(1.0 \%)$ & $16(2.6 \%)$ \\
\hline \multicolumn{4}{|l|}{ Residence* $^{*}$} \\
\hline Urban & $73686(88.3 \%)$ & $2210(85.4 \%)$ & $541(89.0 \%)$ \\
\hline Rural & $9648(11.6 \%)$ & $371(14.3 \%)$ & $61-67$ \\
\hline Missing & $134(0.2 \%)$ & $7(0.3 \%)$ & $\leq 5$ \\
\hline \multicolumn{4}{|l|}{ No of major ADGs } \\
\hline 0 & $57966(69.4 \%)$ & $1699(65.6 \%)$ & $414(68.1 \%)$ \\
\hline 1 & $21012(25.2 \%)$ & 708 (27.4\%) & $145(23.8 \%)$ \\
\hline $2+$ & 4490 (5.4\%) & $181(7.0 \%)$ & $49(8.1 \%)$ \\
\hline \multicolumn{4}{|l|}{ Usual provider of care model } \\
\hline Family health group $†$ & $14482(17.4 \%)$ & $444(17.2 \%)$ & $114(18.8 \%)$ \\
\hline Family health team $\ddagger$ & $22046(26.4 \%)$ & $761(29.4 \%)$ & $135(22.2 \%)$ \\
\hline Family health organisation§ & $18699(22.4 \%)$ & $551(21.3 \%)$ & $140(23.0 \%)$ \\
\hline No model & $25667(30.8 \%)$ & $759(29.3 \%)$ & $203(33.4 \%)$ \\
\hline Comprehensive care modelף & $1745(2.1 \%)$ & $42(1.6 \%)$ & $10-16$ \\
\hline Other & $829(1.0 \%)$ & $31(1.2 \%)$ & $\leq 5$ \\
\hline \multicolumn{4}{|l|}{ Type of surgery } \\
\hline Tonsillectomy & $40135(48.1 \%)$ & $1875(72.4 \%)$ & $561(92.3 \%)$ \\
\hline Implantation of internal devices, tympanic membrane & $33458(40.1 \%)$ & 485 (18.7\%) & $28(4.6 \%)$ \\
\hline Muscle repair of the chest and abdomen: hernia & $6235(7.5 \%)$ & $122(4.7 \%)$ & $9(1.5 \%)$ \\
\hline Knee joint repair & $1955(2.3 \%)$ & $44(1.7 \%)$ & $\leq 5$ \\
\hline Cholecystectomy & $782(0.9 \%)$ & $38(1.5 \%)$ & $\leq 10$ \\
\hline Shoulder surgery & $755(0.9 \%)$ & $18-24$ & $\leq 5$ \\
\hline Nerves in the forearm and wrist & $148(0.2 \%)$ & $\leq 5$ & $0(0.0 \%)$ \\
\hline
\end{tabular}

*Estimates based on Rurality Index of Ontario 2008.

†Family health groups are groups of 3 or more family MDs. Care is provided through regular office hours and extended hours (weekday evenings and/or weekends) and they use fee-for-service plus some incentives and bonuses for services provided to enrolled patients. ${ }^{19}$ \#Family health teams are community-focused primary healthcare organisations that consist of interprofessional teams including MDs, nurse practitioners, registered nurses, social workers, dietitians and other professionals who work together. Physicians are paid through a blended salary model. Other health professionals are paid through salary. ${ }^{19}$

§Family health organisations are groups of 3 or more family MDs who commit to enrol patients; care provided through regular office hours and extended hours based on the number of physicians; services are paid through a blended capitation model plus some incentives and bonuses for services to enrolled patients.

१Comprehensive care models are solo primary care MDs; care is provided through regular office hours plus at least one session of extended hours weekly; use fee-for-service plus some incentives and bonuses for service. ${ }^{19}$ 


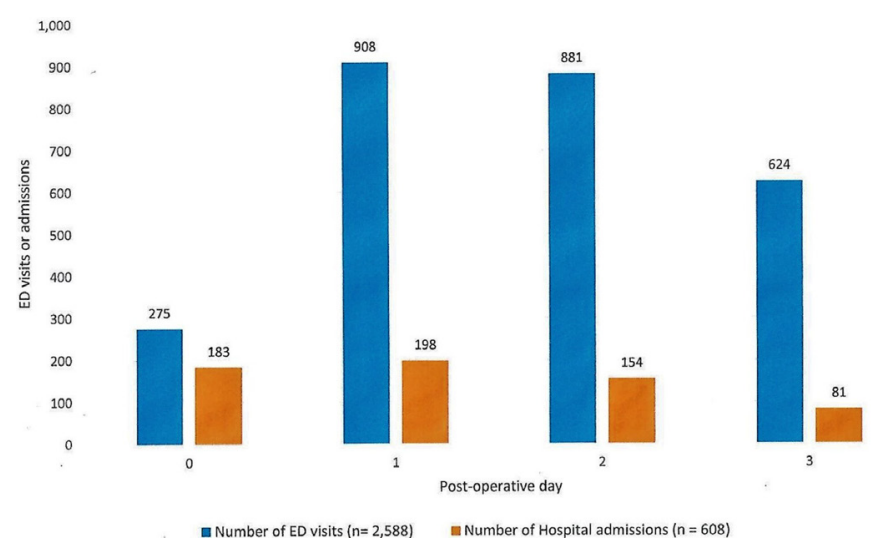

Figure 1 Distribution of emergency department (ED) visits and hospital admission by postoperative day: 2014-2018. All of the ED visits and hospital admissions are displayed as proportions based on the postoperative day.

sample size was sufficient for meaningful comparisons with other surgical procedures. The full adjusted models included all available variables: age, sex, primary care model, LHIN, material deprivation quintile, rural/urban residence, comorbidity (major ADGs) and surgical category. The main reasons for ED use were calculated for all surgical procedures combined and for those surgical procedures with sufficient sample size and volume to avoid small cell frequencies. Hospital admissions were only calculated for all surgical procedures combined due to the small cell frequencies. All analyses were conducted using SAS (SAS Enterprise Guide, V.7.1).

\section{RESULTS}

Between 1 January 2014 and 31 December 2018, 83468 children in Ontario underwent the selected surgical procedures. The mean age was 6.2 (SD 4.4) years, and $44 \%$ were female (table 1 ). The most frequently performed surgical procedures were tonsillectomy $(48.1 \%)$, implantation of internal devices into the tympanic membrane $(40.1 \%)$, and muscle repair of the chest and abdomen (hernia, $7.5 \%)$. A total of $3196(5.9 \%)$ children had an $\mathrm{ED}$ visit or $\mathrm{HA}$ in the first 3 days after surgery. There were $2588(3.1 \%)$ ED visits and $608(0.7 \%)$ HAs (either through the ED or directly). One hundred and three

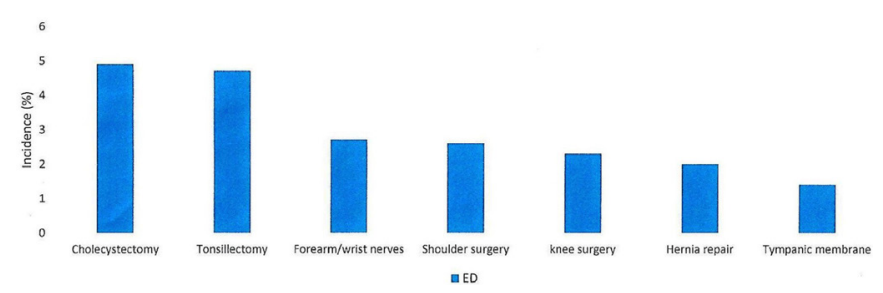

Figure 2 Incidence of emergency department (ED) visits postoperatively by type of surgery: 2014-2018. ED visits are displayed in proportions. All ED visits from day of surgery (postoperative day 0) to postoperative day 3 are included. Patients undergoing cholecystectomy (4.9\%) had the highest incidence of ED use, followed by tonsillectomy (4.7\%).
$(3.9 \%)$ children returned to the ED more than once, for a total of $2688 \mathrm{ED}$ visits. The majority of ED visits occurred on postoperative day $1(908 ; 35.1 \%)$ or $2(881$; $34 \%$ ) (figure 1). Of the 2681 patients who visited the ED at least once, $72.4 \%$ underwent tonsillectomy (table 1). Sixteen children who had a HA were admitted more than once, resulting in 616 HAs. Of the 606 patients who were admitted to hospital at least once, the majority underwent tonsillectomy $(92.3 \%)$.

Patients who underwent cholecystectomy had the highest proportion of ED visits (4.9\%) (figure 2). Children who underwent tonsillectomy $(1.4 \%)$ had the highest proportion of HA. Female children had a higher odds of ED use (adjusted OR 1.18, 95\% CI 1.09 to 1.28) (table 2). Children were more likely to have an ED visit if they lived in a rural setting (adjusted OR 1.29, 95\% CI 1.05 to 1.34) or had a poor socioeconomic status (adjusted OR 1.39, $95 \%$ CI 1.22 to 1.58). The odds of ED use also increased as number of comorbidities increased (2+ADGs; OR 1.35, $95 \%$ CI 1.15 to 1.58 ). The adjusted odds of ED use was lower for all surgical categories compared with cholecystectomy. Acute pain (17.2\%) and haemorrhage (10.9\%) were the most frequent reasons for an ED visit (table 3). Table 4 provides a detailed breakdown of the five most common reasons for an ED visit for children who underwent tonsillectomy, tympanic membrane procedures and hernia repair. The primary reason for admission to hospital was haemorrhage/haematoma (24.8\%), dehydration $(21.9 \%)$ and acute pain $(9.1 \%)$. Due to small cell frequencies, the results for HA for specific surgical procedures are not presented.

\section{DISCUSSION}

This retrospective cohort study describes the rate of unplanned healthcare use after ambulatory surgery in children in Ontario, Canada. Between 2014 and 2018, $3.1 \%$ of children visited the ED and $0.7 \%$ were admitted to hospital during the first 3 days following select ambulatory surgery procedures. The highest proportion of healthcare use was in children who underwent tonsillectomy. The main reason for ED use for all surgery types was unrelieved acute pain or haemorrhage, while the main reason for HAs was haemorrhage and dehydration. Our findings are similar to previously published studies that reported a readmission rate of $1 \%$ to $3.6 \%$ up to 30 days after surgery, with the majority of readmissions occurring between 3 and 7 days after surgery. ${ }^{4-1021}$ The most common reasons for requiring hospital care were also consistent with our findings and included pain, nausea and vomiting, dehydration and haemorrhage. ${ }^{4-10}$

Gilani and Bhattacharyya reported that $4.5 \%$ of children who underwent tonsillectomy on an ambulatory basis had a hospital revisit due to acute pain, haemorrhage, nausea, vomiting and dehydration. ${ }^{9}$ Our findings were similar with children who underwent tonsillectomy having a HA for similar reasons. Lavin et al examined ED visits in children following ambulatory tonsillectomy 
Table 2 Univariate and multivariate ORs and 95\% Cls for ED visit and hospital admissions in the 3 days following ambulatory surgery: 2014-2018

\begin{tabular}{|c|c|c|c|c|c|}
\hline \multirow[b]{3}{*}{ Character } & \multirow[b]{3}{*}{ Total } & \multicolumn{2}{|l|}{ ED visits } & \multicolumn{2}{|c|}{ Hospital admissions } \\
\hline & & Unadjusted & Adjusted $^{*}$ & Unadjusted & Adjusted $^{*}$ \\
\hline & & OR $(95 \% \mathrm{Cl})$ & OR $(95 \% \mathrm{Cl})$ & OR $(95 \% \mathrm{Cl})$ & OR $(95 \% \mathrm{Cl})$ \\
\hline No of patients & 83468 & & & & \\
\hline \multicolumn{6}{|l|}{ Sex (from RPDB) } \\
\hline Male & 46724 & 1.00 & 1.00 & 1.00 & 1.00 \\
\hline Female & 36744 & 1.24 (1.15 to 1.34$)$ & 1.18 (1.09 to 1.28$)$ & 1.22 (1.04 to 1.44$)$ & $1.21(1.03$ to 1.42$)$ \\
\hline \multicolumn{6}{|c|}{ Material deprivation quintile } \\
\hline $\begin{array}{l}\text { 1-Lowest } \\
\text { (reference) }\end{array}$ & 19772 & 1.00 & 1.00 & 1.00 & 1.00 \\
\hline 2 & 18280 & 1.10 (0.98 to 1.25$)$ & $1.10(0.97$ to 1.25$)$ & 1.07 (0.84 to 1.37$)$ & $1.11(0.87$ to 1.42$)$ \\
\hline 3 & 15719 & 1.18 (1.04 to 1.34$)$ & 1.17 (1.03 to 1.33$)$ & 0.95 (0.73 to 1.23$)$ & $1.00(0.77$ to 1.30$)$ \\
\hline 4 & 13822 & $1.40(1.24$ to 1.59$)$ & 1.39 (1.22 to 1.58$)$ & 1.01 (0.78 to 1.32$)$ & $1.06(0.81$ to 1.39$)$ \\
\hline 5-Highest & 15347 & 1.40 (1.23 to 1.58$)$ & 1.37 (1.21 to 1.55$)$ & 1.24 (0.97 to 1.58$)$ & $1.26(0.98$ to 1.61$)$ \\
\hline Missing & 528 & 2.02 (1.36 to 3.01$)$ & $1.92(1.28$ to 2.87$)$ & 4.58 (2.71 to 7.75$)$ & 4.80 (2.79 to 8.28$)$ \\
\hline \multicolumn{6}{|l|}{ Residence† } \\
\hline Urban (reference) & 73686 & 1.00 & 1.00 & 1.00 & 1.00 \\
\hline Rural & 9648 & 1.29 (1.16 to 1.45$)$ & 1.19 (1.05 to 1.34$)$ & $0.93(0.72$ to 1.20$)$ & $0.99(0.75$ to 1.30$)$ \\
\hline \multicolumn{6}{|l|}{ No of major ADGs } \\
\hline 0 (Reference) & 57966 & 1.00 & 1.00 & 1.00 & 1.00 \\
\hline 1 & 21012 & 1.15 (1.06 to 1.26$)$ & 1.12 (1.02 to 1.22$)$ & $0.97(0.80$ to 1.17$)$ & $0.96(0.79$ to 1.16$)$ \\
\hline 2 & 4490 & 1.39 (1.19 to 1.63$)$ & 1.35 (1.15 to 1.58$)$ & 1.53 (1.14 to 2.07$)$ & 1.53 (1.14 to 2.07$)$ \\
\hline \multicolumn{6}{|c|}{ Usual provider of care model } \\
\hline No model (reference) & 25667 & 1.00 & 1.00 & 1.00 & 1.00 \\
\hline Family health group & 14482 & 1.04 (0.92 to 1.17$)$ & 0.99 (0.88 to 1.12$)$ & 1.00 (0.79 to 1.25$)$ & $0.99(0.79$ to 1.26$)$ \\
\hline Family health Team & 22046 & 1.17 (1.06 to 1.30$)$ & 1.08 (0.97 to 1.20$)$ & 0.77 (0.62 to 0.96$)$ & 0.76 (0.61 to 0.95 ) \\
\hline $\begin{array}{l}\text { Family health } \\
\text { organisation }\end{array}$ & 18699 & 1.00 (0.89 to 1.11$)$ & 0.91 (0.81 to 1.02$)$ & 0.95 (0.76 to 1.17$)$ & $0.90(0.72$ to 1.13$)$ \\
\hline $\begin{array}{l}\text { Comprehensive care } \\
\text { model }\end{array}$ & 1745 & 0.81 (0.59 to 1.11 ) & 0.75 (0.55 to 1.03$)$ & 1.01 (0.59 to 1.75$)$ & $0.98(0.57$ to 1.70$)$ \\
\hline Other & 829 & 1.28 (0.88 to 1.84$)$ & 1.03 (0.69 to 1.53$)$ & 0.30 (0.08 to 1.22$)$ & 0.26 (0.06 to 1.10$)$ \\
\hline \multicolumn{6}{|l|}{ Type of surgery } \\
\hline $\begin{array}{l}\text { Cholecystectomy } \\
\text { (reference) }\end{array}$ & 782 & 1.00 & 1.00 & 1.00 & 1.00 \\
\hline Tonsillectomy & 40135 & 0.96 (0.69 to 1.33$)$ & 0.94 (0.67 to 1.33$)$ & $1.83(0.82$ to 4.11$)$ & $1.12(0.49$ to 2.58$)$ \\
\hline $\begin{array}{l}\text { Implantation of } \\
\text { internal devices, } \\
\text { tympanic membrane }\end{array}$ & 33458 & 0.29 (0.21 to 0.40$)$ & 0.28 (0.19 to 0.40$)$ & $0.11(0.04$ to 0.26$)$ & 0.05 (0.02 to 0.13$)$ \\
\hline $\begin{array}{l}\text { Muscle repair of the } \\
\text { chest and abdomen: } \\
\text { hernia }\end{array}$ & 6235 & 0.39 (0.27 to 0.57$)$ & 0.39 (0.26 to 0.57$)$ & $0.19(0.07$ to 0.53$)$ & 0.11 (0.04 to 0.31$)$ \\
\hline Knee joint repair & 1955 & 0.45 (0.29 to 0.70$)$ & 0.47 (0.30 to 0.73$)$ & 0.20 (0.05 to 0.80$)$ & 0.21 (0.05 to 0.83 ) \\
\hline $\begin{array}{l}\text { Nerves in the } \\
\text { forearm and wrist }\end{array}$ & 148 & 0.68 (0.26 to 1.77$)$ & 0.67 (0.26 to 1.73$)$ & $0.00\left(0.00\right.$ to $\left.{ }^{\star \star \star \star}\right)$ & $0.00\left(0.00\right.$ to $\left.^{* \star \star \star}\right)$ \\
\hline Shoulder surgery & 755 & 0.51 (0.29 to 0.88$)$ & $0.50(0.29$ to 0.88$)$ & 0.17 (0.02 to 1.43$)$ & $0.18(0.02$ to 1.50$)$ \\
\hline
\end{tabular}

*Adjusted for age and Local Health Integration Network (results not shown).

†Estimates based on Rurality Index of Ontario 2008.

łJohns Hopkins Aggregated Diagnostic Groups. 
Table 3 Eight common reasons for emergency department (ED) visit and hospital admission for all procedures combined: 2014-2018

\begin{tabular}{|c|c|c|}
\hline Reasons for ED visit & $\mathbf{n}$ & $\%$ of visits \\
\hline Acute pain & 463 & 17.2 \\
\hline Haemorrhage and haematoma & 293 & 10.9 \\
\hline Fever & 195 & 7.3 \\
\hline $\begin{array}{l}\text { Other complications of } \\
\text { procedures, not elsewhere } \\
\text { classified }\end{array}$ & 186 & 6.9 \\
\hline Vomiting & 181 & 6.7 \\
\hline Infection following a procedure & 120 & 4.5 \\
\hline Acute upper airway infection & 84 & 3.1 \\
\hline Dehydration & 72 & 2.7 \\
\hline $\begin{array}{l}\text { Reasons for hospital } \\
\text { admission }\end{array}$ & $\mathbf{n}$ & $\begin{array}{l}\% \text { of } \\
\text { admissions }\end{array}$ \\
\hline Haemorrhage and haematoma & 153 & 24.8 \\
\hline Dehydration & 135 & 21.9 \\
\hline Acute pain & 56 & 9.1 \\
\hline Vomiting & 15 & 2.4 \\
\hline Infection & 13 & 2.1 \\
\hline $\begin{array}{l}\text { Other complications of } \\
\text { procedures }\end{array}$ & 12 & 1.9 \\
\hline Fever & 8 & 1.3 \\
\hline Nausea with vomiting & 7 & 1.1 \\
\hline
\end{tabular}

and reported that $7.4 \%$ had an ED visit, with $1.9 \%$ of these visits due to pain or dehydration. ${ }^{11}$ Children who had non-English-speaking parents and had other health conditions including asthma, pre-term developmental delay, Down syndrome and attention deficit hyperactivity disorder were more likely to have an ED visit postoperatively. Language barriers and comorbid medical conditions made it more difficult for parents and children to adhere to the postoperative pain and hydration regimen they were provided. ${ }^{11}$ In our study, the most common reason was for an ED visit due to unrelieved acute pain. Also, children in our sample had higher odds of ED use if they had two or more comorbid conditions.

A US administrative database study reported the 30-day readmission rate following ambulatory paediatric cholecystectomy as $1.1 \%$, with the most common reasons for readmission being persistent calculus in the biliary duct, abdominal pain and dehydration. ${ }^{8}$ Gould and colleagues reported that $21 \%$ of children were admitted to hospital following cholecystectomy with $14 \%$ admitted for no identifiable reason. ${ }^{7}$ Identifiable reasons for admission included pain and vomiting. ${ }^{7}$ Similar to these studies, the reasons for admission or ED visits in our study were also pain and vomiting. However, in our study, children who underwent ambulatory cholecystectomy had a higher rate of ED visit and HA.
Table 4 Top 5 reasons for emergency department (ED) visits for surgical procedures

\begin{tabular}{|c|c|c|}
\hline Procedure (no of visits) & $\mathbf{n}$ & $\begin{array}{l}\% \text { of } \\
\text { ED visits/ } \\
\text { procedure }\end{array}$ \\
\hline \multicolumn{3}{|l|}{ Tonsillectomy $(n=1950)$} \\
\hline Acute pain & 403 & 20.7 \\
\hline Haemorrhage and haematoma & 238 & 12.2 \\
\hline $\begin{array}{l}\text { Other complications of procedures, } \\
\text { not elsewhere classified }\end{array}$ & 155 & 7.9 \\
\hline Vomiting & 149 & 7.6 \\
\hline Fever & 137 & 7.0 \\
\hline
\end{tabular}

Implantation of internal devices, tympanic membrane $(n=506)$

\begin{tabular}{lrr} 
Fever & 51 & 10.1 \\
\hline Otitis media & 37 & 7.3 \\
\hline Acute upper respiratory infection & 36 & 7.1 \\
\hline Haemorrhage and haematoma & 27 & 5.4 \\
\hline $\begin{array}{l}\text { Acute pain } \\
\text { Hernia (n=125) }\end{array}$ & 26 & 5.2 \\
\hline $\begin{array}{l}\text { Haemorrhage and haematoma } \\
\text { Other complications of procedures }\end{array}$ & 15 & 12.0 \\
\hline $\begin{array}{l}\text { Attention to surgical dressings and } \\
\text { sutures }\end{array}$ & 9 & 8.8 \\
\hline $\begin{array}{l}\text { Acute pain } \\
\begin{array}{l}\text { Disruption of operation wound, not } \\
\text { elsewhere classified }\end{array}\end{array}$ & 7 & 5.6 \\
\hline
\end{tabular}

Acute pain is a common reason for ED visits and HA. Guidelines for opioid prescribing to manage pain in children after surgery state that an optimal postoperative regimen should balance adequate pain control while also supporting recovery, including the return to school and sports. ${ }^{22} 23$ Prescribers should use multimodal analgesia, including local anaesthetics, acetaminophen and non-steroidal anti-inflammatory drugs. Children and parents should be educated regarding the expectations regarding pain and methods of pain management, both before surgery and again in the postoperative period. Education should be delivered verbally and written in plain, non-medical terminology. ${ }^{23}$

Dehydration is a potentially preventable adverse effect, and intravenous hydration protocols that aim to replace fluids lost during the nothing by mouth (NPO) time, intraoperative time and postoperative time can be helpful in decreasing ED visits after surgery. A quality improvement study that focused on intravenous hydration examined ED visits due to dehydration in children who underwent ambulatory tonsillectomy prior to and after the implementation of the protocol. ${ }^{12}$ Younger patients and patients with pre-existing complex chronic conditions were at higher risk of dehydration. After the implementation of a hydration protocol, the ED visits due to dehydration decreased to $0.2 \%$ from $1 \%{ }^{12}$ In our 
study, $2.6 \%$ of children had an ED visit, and $5.9 \%$ had a HA due to dehydration. The implementation of hydration protocols for all paediatric ambulatory surgeries may be helpful in reducing these ED visits and HA.

\section{Strengths and limitations}

The use of administrative data is a strength as it does not rely on patient reports of past experiences, minimising the risk of recall bias. The databases that were used in this study undergo several quality checks by data collection and repository organisations, providing a high level of reliability. Information on outcomes after ambulatory orthopaedic procedures in children is included in this study; this population is not well documented in the published literature. The results of this study could be generalised with caution to the rest of Canada, where universal healthcare provides similar access to services.

The main disadvantage of this study is the small number of hospital admissions which limits the analysis that we were able to complete for this study. In addition, administrative data rely on accurate recording of information that is subject to human error.

\section{CONCLUSION}

This study used administrative data to identify ED visits and HAs following select ambulatory surgery in children. Many children undergo these surgical procedures without any complications or unanticipated hospital visits following discharge. However, we found that just under $6 \%$ of children had an ED visit or HA following elective ambulatory surgery in Ontario between 2014 and 2018, with the most common reasons for visit or admission being acute pain, haemorrhage and dehydration. The results of this study can be used by both clinicians and administrators to identify those children who are at high risk of ED use or HA and implement strategies to help reduce $\mathrm{ED}$ visits and $\mathrm{HA}$.

Prior to the COVID-19 pandemic, there was an increasing trend in the number of ambulatory paediatric surgical procedures performed in Canada and around the world. The goal of paediatric ambulatory surgery is to improve access to care. However, the restrictions associated with the COVID-19 pandemic and the need to limit HAs have created a backlog of elective and urgent surgical procedures for children and adults. Between February and 30 April 2019, there were 181544 ambulatory surgery procedures were completed in Ontario, Canada. ${ }^{24} \mathrm{~A}$ similar number of ambulatory surgery procedures were scheduled and subsequently cancelled in $2020 .^{24}$ As healthcare teams look for creative ways to safely perform surgical procedures, ambulatory surgery may become an attractive option. These teams should proactively try to prevent the common reasons why children return to hospital. The effectiveness of interventions that prevent readmissions should continue to be examined.

\section{Author affiliations}

${ }^{1}$ School of Nursing, Queen's University, Kingston, Ontario, Canada

${ }^{2}$ School of Nursing and Midwifery, Mount Royal University, Calgary, Alberta, Canada

${ }^{3}$ Department of Anesthesiology, University of Calgary Faculty of Medicine, Calgary, Alberta, Canada

${ }^{4}$ Institute for Clinical Evaluative Sciences, Queen's University, Toronto, Ontario, Canada

${ }^{5}$ Department of Orthopaedic Surgery, North York General Hospital, Toronto, Ontario, Canada

\section{Twitter Monakshi Sawhney @Mona_Sawhney}

Contributors All authors contributed substantially to conception and design, or acquisition of data, or analysis and interpretation of data. All authors were involved in drafting the article or revising it critically for important intellectual content. All authors gave final approval of the version to be published and agree to act as guarantor of the work (ensuring that questions related to any part of the work are appropriately investigated and resolved).

Funding This study was funded by an Ontario Ministry of Health and Long-Term Care (MOHLTC) Applied Health Research Question grant (Project Trim 20160800 186 000) and a Queen's University School of Nursing Research Development Fund grant. This study was supported by the Institute for Clinical Evaluative Sciences (ICES), which is funded by an annual grant from the MOHLTC. The opinions, results and conclusions reported in this paper are those of the authors and are independent from the funding sources. No endorsement by ICES or the Ontario MOHLTC is intended or should be inferred.

Competing interests None declared.

Patient consent for publication Not applicable.

Ethics approval This study was approved by the institutional review board at Sunnybrook Health Sciences Centre, Toronto, Canada and the Queen's University Health Science and Affiliated Teaching Hospitals Research Ethics Board, Kingston, Canada (HSREB \#6017706). Patients were not involved in the development of this study. This study was conducted using de-identified administrative databases held by ICES; therefore, individual participant consent was not obtained.

Provenance and peer review Not commissioned; externally peer reviewed.

Data availability statement Data are available on reasonable request. The data that support the findings of this study are available from ICES https://www.ices.on. $\mathrm{ca} /$ but restrictions apply to the availability of these data, which were used under license for the current study, and so are not publicly available. Data are however available from the authors upon reasonable request and with permission of ICES.

Supplemental material This content has been supplied by the author(s). It has not been vetted by BMJ Publishing Group Limited (BMJ) and may not have been peer-reviewed. Any opinions or recommendations discussed are solely those of the author(s) and are not endorsed by BMJ. BMJ disclaims all liability and responsibility arising from any reliance placed on the content. Where the content includes any translated material, BMJ does not warrant the accuracy and reliability of the translations (including but not limited to local regulations, clinical guidelines, terminology, drug names and drug dosages), and is not responsible for any error and/or omissions arising from translation and adaptation or otherwise.

Open access This is an open access article distributed in accordance with the Creative Commons Attribution Non Commercial (CC BY-NC 4.0) license, which permits others to distribute, remix, adapt, build upon this work non-commercially, and license their derivative works on different terms, provided the original work is properly cited, appropriate credit is given, any changes made indicated, and the use is non-commercial. See: http://creativecommons.org/licenses/by-nc/4.0/.

\section{ORCID iDs}

Monakshi Sawhney http://orcid.org/0000-0001-5399-1715

Elizabeth G VanDenKerkhof http://orcid.org/0000-0003-4287-346X

David H Goldstein http://orcid.org/0000-0003-2055-3246

Genevieve Pare http://orcid.org/0000-0002-3714-9744

Ian Mayne http://orcid.org/0000-0002-7935-5781

Joan Tranmer http://orcid.org/0000-0001-5192-5992

\section{REFERENCES}

1 Nordin AB, Shah SR, Kenney BD. Ambulatory pediatric surgery. Semin Pediatr Surg 2018;27:75-8. 
2 Miller DJ, Nelson SE, Shah AS, et al. Outpatient pediatric orthopedic surgery. Orthop Clin North Am 2018;49:55-62.

3 Canadian Institute for Health Information. NACRS Emergency Department Visits and Length of Stay by Province/Territory, 20182019. Ottawa, ON: ClHI, 2019. https://www.cihi.ca/en/quick-stats

4 Murto KTT, Katz SL, Mclsaac DI, et al. Pediatric tonsillectomy is a resource-intensive procedure: a study of Canadian health administrative data. Can J Anaesth 2017;64:724-35.

5 Johnson RF, Chang A, Mitchell RB. Nationwide readmissions after tonsillectomy among pediatric patients - United States. Int J Pediatr Otorhinolaryngol 2018;107:10-13.

6 McKeon M, Medina G, Kawai K, et al. Readmissions following ambulatory pediatric endoscopic sinus surgery. Laryngoscope 2019;129:2681-6.

7 Gould JL, Poola AS, St. Peter SD, et al. Same day discharge protocol implementation trends in laparoscopic cholecystectomy in pediatric patients. J Pediatr Surg 2016;51:1936-8.

8 Sacco Casamassima MG, Gause C, Yang J, et al. Safety of outpatient laparoscopic cholecystectomy in children: analysis of 2050 elective ACS NSQIP-pediatric cases. Pediatr Surg Int 2016;32:541-51.

9 Gilani S, Bhattacharyya N. Revisit rates for pediatric tonsillectomy: an analysis of admit and discharge times. Ann Otol Rhinol Laryngol 2020;129:110-4.

10 Whippey A, Kostandoff G, Ma HK, et al. Predictors of unanticipated admission following ambulatory surgery in the pediatric population: a retrospective case-control study. Paediatr Anaesth 2016;26:831-7.

11 Lavin J, Lehmann D, Silva AL, et al. Variables associated with pediatric emergency department visits for uncontrolled pain in postoperative adenotonsillectomy patients. Int $J$ Pediatr Otorhinolaryngol 2019;123:10-14.

12 Hession-Laband E, Melvin P, Shermont $\mathrm{H}$, et al. Reducing readmissions post-tonsillectomy: a quality improvement study on intravenous hydration. J Healthc Qual 2018;40:217-27.

13 Sawhney M, Goldstein DH, Wei X, et al. Pain and haemorrhage are the most common reasons for emergency department use and hospital admission in adults following ambulatory surgery: results of a population-based cohort study. Perioper Med 2020;9:25.

14 Canadian Institute for Health Information. A snapshot of health care in Canada as demonstrated by top 10 Lists, 2011. Ottawa, ON: CIHI publication, 2012. https://secure.cihi.ca/free_products/ Top10ReportEN-Web.pdf

15 Canadian Institute for Health Information. CCl (Canadian classification of health interventions), 2017. Available: https:// www cihi ca/en/submit-data-and-view-standards/codes-andclassifications/cci [Accessed 30 Jan 2021].

16 Local Health Integration Network. Ontario's LHINs. Available: http:// www.Ihins.on.ca/ [Accessed 4 Jan 2021].

17 Durbin A, Moineddin R, Lin E, et al. Examining the relationship between neighbourhood deprivation and mental health service use of immigrants in Ontario, Canada: a cross-sectional study. BMJ Open 2015;5:e006690.

18 Government of Ontario. health care options, 2017. Available: https://www ontario ca/locations/ health/?gclid=CPX6jdOLs9MCFc64wAodeygNKA [Accessed 30 Jan 2021].

19 Glazier RH, Hutchinson B, Kopp A. Comparison of family health teams to other Ontario primary care models, 2004/05 to 2011/12. Toronto: ICES, 2015.

20 The Johns Hopkins University. The Johns Hopkins ACG System. Available: https://www.hopkinsacg.org/ [Accessed 1 Feb 2021].

21 Viera AJ. Odds ratios and risk ratios: what's the difference and why does it matter? South Med J 2008;101:730-4.

22 Health Quality Ontario. Opioid prescribing for acute pain. Toronto: Queen's Printer for Ontario, 2018.

23 Kelley-Quon LI, Kirkpatrick MG, Ricca RL, et al. Guidelines for opioid prescribing in children and adolescents after surgery: an expert panel opinion. JAMA Surg 2021;156:76-90.

24 Canadian Institute for Health Information. Estimating planned surgical cancellations due to COVID-19 using historical data - data tables. Ottawa, ON: CIHI, 2020. https://www.cihi.ca/en/quick-stats 